\title{
DESIGNING A LAYOUT USING SCHMIGALLA METHOD COMBINED WITH SOFTWARE TOOL VISTABLE
}

\author{
Banduka, N. ${ }^{* * *}$; Mladineo, M. ${ }^{*} \&$ Eric, M. ${ }^{* *}$ \\ * University of Split, Faculty of Electrical Engineering, Mechanical Engineering and Naval \\ Architecture, Ruđera Boškovića 32, 21000 Split, Croatia \\ ** University of Kragujevac, Faculty of Engineering, Sestre Janjic 6, 34000 Kragujevac, Serbia \\ E-Mail: nbanduka@fesb.hr, mmladine@fesb.hr, ericm@kg.ac.rs
}

\begin{abstract}
In this paper, a design of optimal facility layout, for already existing factory, using a Schmigalla method combined with software tool visTABLE for layout modelling and optimization is presented. It is called static facility layout planning. Schmigalla method belongs to heuristic type of methods. These method types should be combined with some other methods or tools. Combination of this method in conceptual phase and software visTABLE for layout modelling and optimization in optimization phase is presented. For real-world industrial application, this particular combination is obtaining significant improvement results. Layout designing was realized on a real production process example with 15 different products. In the first part of the paper, a production process with all the data is presented. After that, in the second part, a theoretical and mathematical model of Schmigalla method as a base for layout modelling was used. Then, in the third part, Schmigalla method layout transformation was practically (virtually) realized with software visTABLE. In the fourth part, after layout realization of a virtual layout model, software visTABLE was additionally used (manually and automatically) for finding an optimal layout solution.

(Received in September 2016, accepted in February 2017. This paper was with the authors 2 months for 2 revisions.)
\end{abstract}

Key Words: Facility Layout Problems, Schmigalla Method, visTABLE, Layout Optimization

\section{INTRODUCTION}

Study by Sule [1] points out that 30-75 \% of total costs of a product are material handling costs. Furthermore, $20-50 \%$ of total operating costs in manufacturing companies are material handling costs [2]. However, with good material handling management and adequate facility layout positioning, total product and operation costs can be reduced. These types of problems are called Facility layout problems (FLP). FLP are usually presented in facility planning phase. This phase consists of facility location, facility system design, facility layout design and handling system design [3].

FLP is term for determining combinatorial optimisation problems which influence physical optimisation of real production systems. Facilities are in the middle of FLP. According to Heragu [4] facility represents entity, which facilitates the performance of any job. In this paper, focus is on industrial plants, so facility can be: machine tool, workplace, manufacturing cell, whole manufacturing plant, warehouse, production system, etc. Facility can be widely defined as environment in which people are in interaction with machines, materials, tools and other equipment with a common goal - manufacturing a product or providing a service. There are two different FLP types, static FLP and dynamic FLP [4, 5]. This paper is focused on static FLP for already existing infrastructure.

There are few authors who have provided review papers with different approaches to solving of FLP. Some of those often used approaches are [6, 7]: exact, approximated, heuristic, and meta-heuristic. In this paper a heuristic method, named Schmigalla method, is used. This type of heuristic method is a construction type, and usually it should be combined with some other improvement methods or tools. Some authors recommend genetic algorithm 
which can be very useful $[8,9]$. Schmigalla method is given as a result of mathematical and theoretical model. But this model does not find optimal layout, in most of the cases. That is the main reason why it is necessary to combine it with some other methods or tools. In this paper, software tool visTABLE is used. VisTABLE can give high degree of objectivity and, at the same time, practical (virtual) model. This software has integrated combination of virtual reality (VR) and layout optimization functions. The usage of software for layout optimization becomes usual practice due to efficiency increase [7, 10].

Layout designing was realized in a real production process example for producing 15 different products. First, a production process with all the data is presented. After that, a theoretical and mathematical of Schmigalla method as a base for layout modelling was used. Then, Schmigalla method layout transformation was practically (virtually) realized with software visTABLE. At the end, after layout realization of a virtual layout model, software visTABLE was additionally used (manually and automatically) for finding an optimal layout solution.

\section{SCHMIGALLA METHOD DESCRIPTION}

As it has already been mentioned, Schmigalla method belongs to heuristic type of layout planning methods. Heuristic algorithms are usually classified as construction and improvement type of algorithms. Generally, construction based algorithms usually do not find optimal solution, because they are simplified, so it is recommended to combine them with other algorithms or methods. Opposite to this, there are improvement based algorithms which are feasible and they can be easily combined with construction methods if it is needed [7]. There are lots of software packages for heuristic algorithms identified by Singh and Sharma [7] and their difference is in objectivity and adjacency.

Schmigalla method is the precursor of triangle method improved by Schmigalla in 1970 [11]. That is why it has another name, Schmigalla method. Shortcomings of triangle method are in defining of two first starting work places, and in assignment of other work places. But the biggest problem with this method was absence of algorithm function. Those were the main improvements by Schmigalla [12].

Schmigalla method consists of network of equilateral triangles where vertices represent potential locations for workstations. Authors Ficko and Palcic [9] highlight that this method is extremely useful for designing new facility layouts and for analysing of already existing ones. Krolczyk et al. [13] presented case study where Schmigalla method was used in automotive industry. So this method is applicable in practise, also.

Schmigalla [14] proposed modified triangle method (a.k.a. Schmigalla method) procedure for placing workstations in four steps:

- Step I: First, two starting workstations should be selected. These two workstations make a base line in triangular network. Selection should be made by taking two workstations with the highest amount of material flow (If there is more than one pair with the highest amount, then selection should be made arbitrarily between these two [12]).

- Step II: After the base line forming, third workstation should be selected among workstations which are not yet selected. Next workstation selection is based on amount of material flow with earlier selected workstations. Workstation with highest amount is selected and it creates a triangle in triangular network.

- Step III: Next workstation is selected based on cumulative sum of material flow between earlier selected workstations and non-selected workstations. Workstation with the highest sum should be selected and placed into triangular network next to the pair with whom it has highest material flow.

- Step IV: Third step is repeated until all workstations are placed in triangular network. 
However, there are some shortcomings related to this method identified by various authors:

- Absence of objectivity [7].

- Workplace area is not taken into account. So, spacious structure needs to be adapted to the space of every individual workplace after calculation $[9,12]$.

- The distances between neighbouring workstations are equal [9].

- The costs per distance travelled between workstations are constant [9].

- Calculation of more than 10 workstations is becoming complex and time-consuming [9].

\section{SOFTWARE VISTABLE - FOR LAYOUT MODELING AND} OPTIMIZATION

Software visTABLE [15] is suitable for factory planning, optimization, evaluation, and visualization. This software has integrated planning functions for instant validation of layouts. So, its main purpose is factory layout planning. The second function is very user friendly virtual reality (VR) 3D modelling system. A VR can provide a practical (virtual) objectivity in combination with theoretical (mathematical) model. The use of VR for factory layout modelling is very important. Often happens that theoretical models do not fit into existing factory layout after practical realization. Therefore, by the use of virtual factory models, wastes and additional costs can be avoided, and it is less time-consuming. Furthermore, it can also be used for other purposes, for example, education. Also, visTABLE's architecture provides distribution of business via internet, which is useful for group planning and modelling [16]. The areas of application proposed by visTABLE ${ }^{\circledR}$ touch company are [15]: factory and layout planning, material flow analysis, implementation of results of a value stream mapping, optimization of logistics processes, assembly planning, scenario planning, running route organization, workshops, etc. Software visTABLE is also recognized in industry, especially in Germany.

There are various authors who have used visTABLE in their research. Horejsi and Polcar [17] used visTABLE's automatic converter during layout projecting, and compared it with another developed automatic converter. Černý and Bureš [18] used it as one of three tools for virtual layout projection and analysis with ergonomic aspect. Research was realized in a group of workplaces and whole company layout, but they avoid using it for individual workplace modelling and analysis. Horbach et al. [19] used visTABLE in planning and visualization of concept of building blocks for adoptable factory systems in the experimental and digital factories. Spath et al. [20] did layout planning for assembling workstations with workers. VisTABLE was also used in study with integration of ERP systems, for virtual modelling of ERP systems by Szendrei et al. [21]. This software was concretely used for making of one virtual structure of OEM and its internal transport systems. Authors mentioned that visTABLE saved a lot of time and money by avoiding necessity to make a physical environment. Beside this industrial purpose, visTABLE has been also widely used for education [17]. In general software visTABLE has already been widely used in literature and especially for layout modelling and optimization.

\section{EXAMPLE}

\subsection{Production process data}

For a serious layout planning it is necessary to have production process data. In this case, an arbitrary model of a company which produces 15 different products on 17 workstations is taken as production process. According to this production process input data for realization of 
Schmigalla method are defined, as well as for defining building area, workstation areas, input and output warehouse, transport units, cantilever shelving, etc. All data is calculated according to input data (customer demand) and models from literature [12]. Some of the main things to define are areas, especially for workstations, warehouses, and buildings, since Schmigalla method defines layout for production process only. All this data is voluminous, so only the most important for the example are highlighted (see Table I and Table II).

Table I: Areas predicted for workstations, for different processes.

\begin{tabular}{|c|l|c|c|}
\hline No. & \multicolumn{1}{|c|}{ Process } & Machine & ${\text { Area of workstation in } \mathbf{~}^{2}}^{2}$ \\
\hline 1 & Sawing & SELECT-O-MAT 320 & 15.84 \\
\hline 2 & Grinding & $3451 \mathrm{~B}$ & 7.50 \\
\hline 3 & Drilling & SB-3 & 2.91 \\
\hline 4 & Milling & GU-2 & 27.22 \\
\hline 5 & Vertical machining processing & MCV32 & 9.36 \\
\hline 6 & Pillar drilling & BRB-4 & 13.20 \\
\hline 7 & Universal lathing & D-420/1500 & 42.84 \\
\hline 8 & Grinding & 3 A130 & 18.36 \\
\hline 9 & Grinding & VR2-1500 & 25.74 \\
\hline 10 & Milling & RAPID 1R & 51.71 \\
\hline 11 & Grinding & BG01 & 7.50 \\
\hline 12 & Lathing & OFA 16 & 13.05 \\
\hline 13 & Machining process & SOK-110 & 28.80 \\
\hline 14 & Planing & H-85-A & 17.92 \\
\hline 15 & Handmade & Manual work & 9 \\
\hline 16 & Painting & Manual work & 9 \\
\hline 17 & Heat treatment & Manual work & 9 \\
\hline
\end{tabular}

Table II: Required area in total.

\begin{tabular}{|l|c|}
\hline \multicolumn{1}{|c|}{ Required area } & $\mathbf{~ m}^{\mathbf{2}}$ \\
\hline Input warehouse & 80.75 \\
\hline Output warehouse & 87.38 \\
\hline Production & 763.43 \\
\hline Sanitary & 25 \\
\hline Office & 9 \\
\hline Tool room & 9 \\
\hline Control department & 9 \\
\hline In total & 983.56 \\
\hline
\end{tabular}

With the definition of these areas, half of the operational jobs are finished. The only operational thing left is definition of mathematical and theoretical Schmigalla method layout model. And then factory layout can be simulated with software visTABLE.

\subsection{Schmigalla method realization}

According to one of identified problems from literature, calculation of more than 10 workstations is complex and time-consuming [9]. So, chosen example is with 17 workstations for calculation. Chosen matrix of material flow between workstations with input data is shown in Table III. This matrix was transferred to non-oriented matrix of material flow, shown in Table IV. The highest amount of material flow between workstations was 61 (see Table IV), so workstations selected for starting line are no. 9 and 3. 
Table III: Matrix of material flow between workstations.

\begin{tabular}{|c|c|c|c|c|c|c|c|c|c|c|c|c|c|c|c|c|c|}
\hline $\mathbf{F} / \mathbf{T}$ & $\mathbf{1}$ & $\mathbf{2}$ & $\mathbf{3}$ & $\mathbf{4}$ & $\mathbf{5}$ & $\mathbf{6}$ & $\mathbf{7}$ & $\mathbf{8}$ & $\mathbf{9}$ & $\mathbf{1 0}$ & $\mathbf{1 1}$ & $\mathbf{1 2}$ & $\mathbf{1 3}$ & $\mathbf{1 4}$ & $\mathbf{1 5}$ & $\mathbf{1 6}$ & $\mathbf{1 7}$ \\
\hline $\mathbf{1}$ & & & & 20 & & & 11 & & 17 & & & & 55 & & & & \\
\hline $\mathbf{2}$ & & & 24 & & & & & & & & & & & & & & \\
\hline $\mathbf{3}$ & & & & & & & & & 44 & & & & 3 & & 24 & & \\
\hline $\mathbf{4}$ & & & 20 & & 8 & & & & & & & 10 & & 20 & 47 & & \\
\hline $\mathbf{5}$ & & & & & & 8 & & & & & & & & & & & \\
\hline $\mathbf{6}$ & & & & & & & 21 & & & & & & & & & 8 & \\
\hline $\mathbf{7}$ & & & 7 & 57 & 4 & & & & 2 & & & 3 & & & & & \\
\hline $\mathbf{8}$ & & 48 & & & & & & & & & & & & & & & \\
\hline $\mathbf{9}$ & & & 17 & & & & & 2 & & & & & & & 44 & & \\
\hline $\mathbf{1 0}$ & & & & 2 & & & & & & & & & & & & & \\
\hline $\mathbf{1 1}$ & & & & & & & & 24 & & & & & & & & & \\
\hline $\mathbf{1 2}$ & & & & & & & & & & & & & & 3 & 10 & & \\
\hline $\mathbf{1 3}$ & & & & & & & 58 & & & & & & & & & & \\
\hline $\mathbf{1 4}$ & & & & & & & & & & & & & & & 20 & 24 & \\
\hline $\mathbf{1 5}$ & & & & & 21 & 20 & & 15 & & & & & & & & & \\
\hline $\mathbf{1 6}$ & & & & 8 & & & 4 & & & & & & & & & & \\
\hline $\mathbf{1 7}$ & & & & & & & & 21 & & & 24 & & & & & & \\
\hline
\end{tabular}

Table IV: Non-oriented matrix of material flow between workstations.

\begin{tabular}{|c|c|c|c|c|c|c|c|c|c|c|c|c|c|c|c|c|c|}
\hline F/T & $\mathbf{1}$ & $\mathbf{2}$ & $\mathbf{3}$ & $\mathbf{4}$ & $\mathbf{5}$ & $\mathbf{6}$ & $\mathbf{7}$ & $\mathbf{8}$ & $\mathbf{9}$ & $\mathbf{1 0}$ & $\mathbf{1 1}$ & $\mathbf{1 2}$ & $\mathbf{1 3}$ & $\mathbf{1 4}$ & $\mathbf{1 5}$ & $\mathbf{1 6}$ & $\mathbf{1 7}$ \\
\hline $\mathbf{1}$ & & & & & & & & & & & & & & & & & \\
\hline $\mathbf{2}$ & & & & & & & & & & & & & & & & & \\
\hline $\mathbf{3}$ & & 24 & & & & & & & & & & & & & & & \\
\hline $\mathbf{4}$ & 20 & & 20 & & & & & & & & & & & & & & \\
\hline $\mathbf{5}$ & & & & 8 & & & & & & & & & & & & & \\
\hline $\mathbf{6}$ & & & & & 8 & & & & & & & & & & & & \\
\hline $\mathbf{7}$ & 11 & & 7 & 57 & 4 & 21 & & & & & & & & & & & \\
\hline $\mathbf{8}$ & & 48 & & & & & & & & & & & & & & & \\
\hline $\mathbf{9}$ & 17 & & 61 & & & & 2 & 2 & & & & & & & & & \\
\hline $\mathbf{1 0}$ & & & & 2 & & & & & & & & & & & & & \\
\hline $\mathbf{1 1}$ & & & & & & & & 24 & & & & & & & & & \\
\hline $\mathbf{1 2}$ & & & & 10 & & & 3 & & & & & & & & & & \\
\hline $\mathbf{1 3}$ & 55 & & 3 & & & & 58 & & & & & & & & & & \\
\hline $\mathbf{1 4}$ & & & & 20 & & & & & & & & 3 & & & & & \\
\hline $\mathbf{1 5}$ & & & 24 & 47 & 21 & 20 & & 15 & 44 & & & 10 & & 20 & & & \\
\hline $\mathbf{1 6}$ & & & & 8 & & 8 & 4 & & & & & & & 24 & 20 & & \\
\hline $\mathbf{1 7}$ & & & & & & & & 21 & & & 24 & & & & 24 & & \\
\hline
\end{tabular}

After defining workstations for the base line of a triangle in triangular network, next workstations are defined (see Table V) according to earlier presented Schmigalla method steps. Calculation of positions of workstations starts with workstations no. 9 and 3, because these workstations were with the highest flow. Next workstation selected is workstation no. 15 , as it can be noticed from Table V. Workstation no. 15 has a maximal cumulative intensity flow with already selected workstations. After that, Schmigalla method continues according to already described steps.

After calculations of material flow between workstations is finished, the achieved triangular network looks like that in Fig. 1. The highest intensity of flow is presented respectively from higher to lower with next colours: red, green, and blue. 
Banduka, Mladineo, Eric: Designing a Layout Using Schmigalla Method Combined with ...

Table V: Calculation for selection of next positions in the triangular network.

\begin{tabular}{|c|c|c|c|c|c|c|c|c|c|c|c|c|c|c|c|c|c|}
\hline No. & $\mathbf{1}$ & $\mathbf{2}$ & $\mathbf{3}$ & $\mathbf{4}$ & $\mathbf{5}$ & $\mathbf{6}$ & $\mathbf{7}$ & $\mathbf{8}$ & $\mathbf{9}$ & $\mathbf{1 0}$ & $\mathbf{1 1}$ & $\mathbf{1 2}$ & $\mathbf{1 3}$ & $\mathbf{1 4}$ & $\mathbf{1 5}$ & $\mathbf{1 6}$ & $\mathbf{1 7}$ \\
\hline $\mathbf{9}$ & 17 & 0 & 61 & 0 & 0 & 0 & 2 & 2 & $*$ & 0 & 0 & 0 & 0 & 0 & 44 & 0 & 0 \\
\hline $\mathbf{3}$ & 0 & 24 & $*$ & 20 & 0 & 0 & 7 & 0 & & 0 & 0 & 0 & 3 & 0 & 24 & 0 & 0 \\
\hline \hline$\sum$ & 17 & 24 & & 20 & 0 & 0 & 9 & 2 & & 0 & 0 & 0 & 3 & 0 & 68 & 0 & 0 \\
\hline $\mathbf{1 5}$ & 0 & 0 & & 47 & 21 & 20 & 0 & 15 & & 0 & 0 & 10 & 0 & 20 & $*$ & 20 & 24 \\
\hline \hline$\sum$ & 17 & 24 & & 67 & 21 & 20 & 9 & 17 & & 0 & 0 & 10 & 3 & 20 & & 20 & 24 \\
\hline $\mathbf{4}$ & 20 & 0 & & $*$ & 8 & 0 & 57 & 0 & & 2 & 0 & 10 & 0 & 20 & & 8 & 0 \\
\hline \hline$\sum$ & 37 & 24 & & & 29 & 20 & 63 & 17 & & 2 & 0 & 20 & 3 & 40 & & 28 & 24 \\
\hline $\mathbf{7}$ & 11 & 0 & & & 4 & 21 & $*$ & 0 & & 0 & 0 & 3 & 58 & 0 & & 4 & 0 \\
\hline \hline$\sum$ & 48 & 24 & & & 33 & 41 & & 17 & & 2 & 0 & 23 & 61 & 40 & & 32 & 24 \\
\hline $\mathbf{1 3}$ & 55 & 0 & & & 0 & 0 & & 0 & & 0 & 0 & 0 & $*$ & 0 & & 0 & 0 \\
\hline \hline$\sum$ & 113 & 24 & & & 33 & 41 & & 17 & & 2 & 0 & 23 & & 40 & & 32 & 24 \\
\hline $\mathbf{1}$ & $*$ & 0 & & & 0 & 0 & & 0 & & 0 & 0 & 0 & & 0 & & 0 & 0 \\
\hline \hline$\sum$ & & 24 & & & 33 & 41 & & 17 & & 2 & 0 & 23 & & 40 & & 32 & 24 \\
\hline $\mathbf{6}$ & & 0 & & & 8 & $*$ & & 0 & & 0 & 0 & 0 & & 0 & & 8 & 0 \\
\hline \hline$\sum$ & & 24 & & & 41 & & & 17 & & 2 & 0 & 23 & & 40 & & 40 & 24 \\
\hline $\mathbf{5}$ & & 0 & & & $*$ & & & 0 & & 0 & 0 & 0 & & 0 & & 0 & 0 \\
\hline \hline$\sum$ & & 24 & & & & & & 17 & & 2 & 0 & 23 & & 40 & & 40 & 24 \\
\hline $\mathbf{1 4}$ & & 0 & & & & & & 0 & & 0 & 0 & 0 & & $*$ & & 24 & 0 \\
\hline \hline$\sum$ & & 24 & & & & & & 17 & & 2 & 0 & 23 & & & & 64 & 24 \\
\hline \hline $\mathbf{1 6}$ & & 0 & & & & & & 0 & & 0 & 0 & 3 & & & & $*$ & 0 \\
\hline \hline$\sum$ & & 24 & & & & & & 17 & & 2 & 0 & 26 & & & & & 24 \\
\hline $\mathbf{1 2}$ & & 0 & & & & & & 0 & & 0 & 0 & $*$ & & & & & 0 \\
\hline \hline$\sum$ & & 24 & & & & & & 17 & & 2 & 0 & & & & & & 24 \\
\hline $\mathbf{1 7}$ & & 0 & & & & & & 21 & & 0 & 24 & & & & & & $*$ \\
\hline \hline$\sum$ & & 24 & & & & & & 38 & & 2 & 24 & & & & & & \\
\hline $\mathbf{8}$ & & 48 & & & & & & $*$ & & 0 & 24 & & & & & & \\
\hline \hline$\sum$ & & 72 & & & & & & & & 2 & 48 & & & & & & \\
\hline $\mathbf{2}$ & & $*$ & & & & & & & & 0 & 0 & & & & & & \\
\hline \hline$\sum$ & & & & & & & & & & 2 & 48 & & & & & & \\
\hline $\mathbf{1 1}$ & & & & & & & & & & 0 & $*$ & & & & & & \\
\hline \hline$\sum$ & & & & & & & & & & 2 & & & & & & & \\
\hline $\mathbf{1 0}$ & & & & & & & & & & $*$ & & & & & & & \\
\hline \hline
\end{tabular}

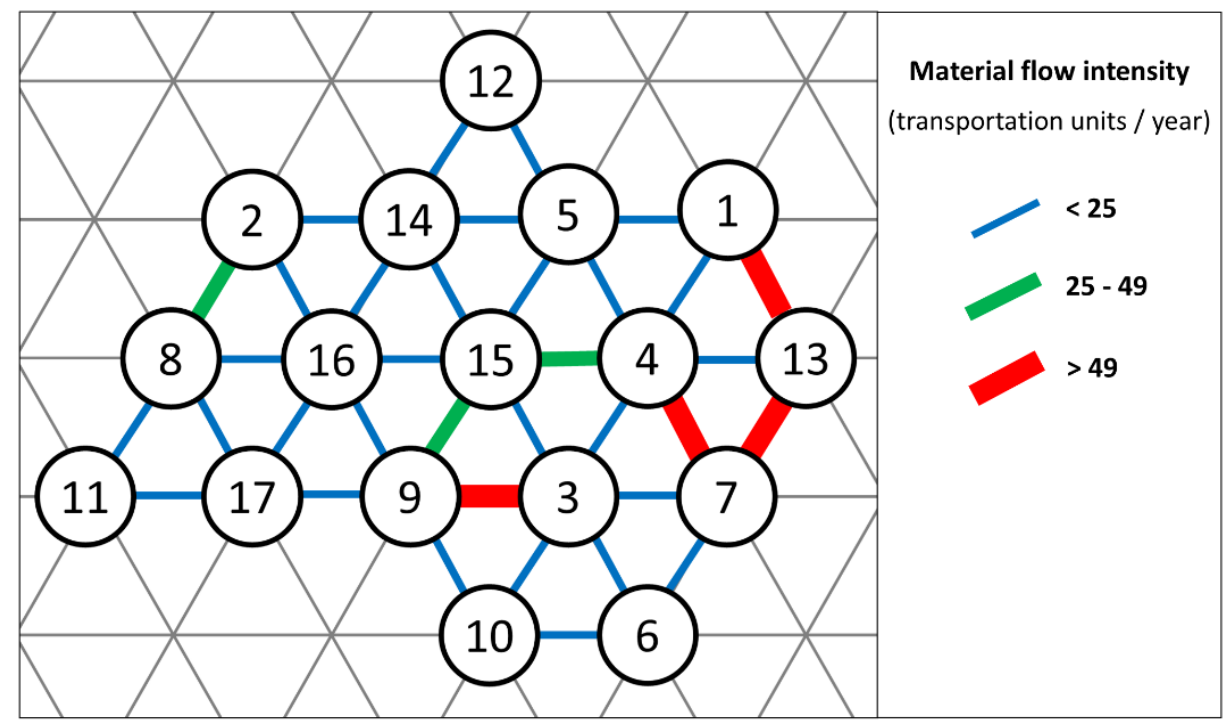

Figure 1: Achieved triangular network. 


\subsection{Transformation from Schmigalla to visTABLE}

One of the biggest shortcomings of Schmigalla method is transformation to the real physical environment. In Fig. 2 transformation of Schmigalla method's layout to 2D layout in visTABLE is presented. This is an ideal case, where same areas of workstations and same distances between workstations are taken into account. These are two shortcomings of Schmigalla method, also. With using of software visTABLE realistic workstation areas are taken into account. Therefore, more realistic scenario of Schmigalla method's layout transformation is presented in Fig. 3. However, transportation route between workstations is still missing and workstations no. 11 and 17 are closest to input warehouse, which is not ideal case, because most of the products have first operation on workstation no. 1. These aspects are taken into account in the following step.

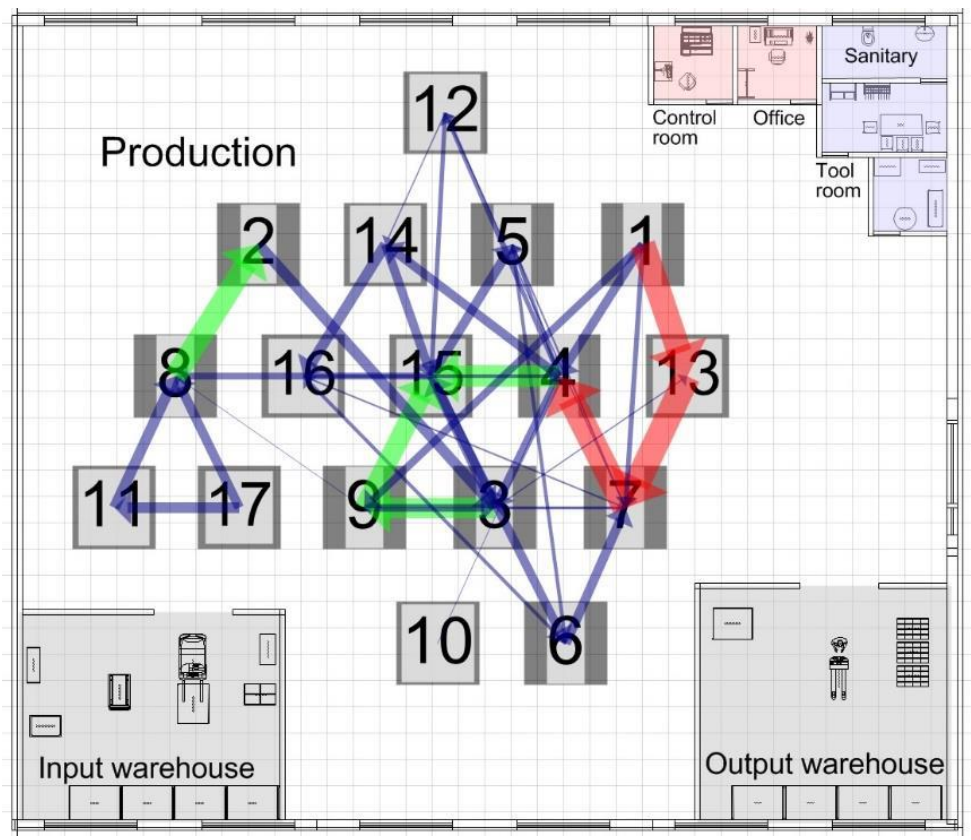

Figure 2: Transformation from Schmigalla method's layout to 2D layout in visTABLE.

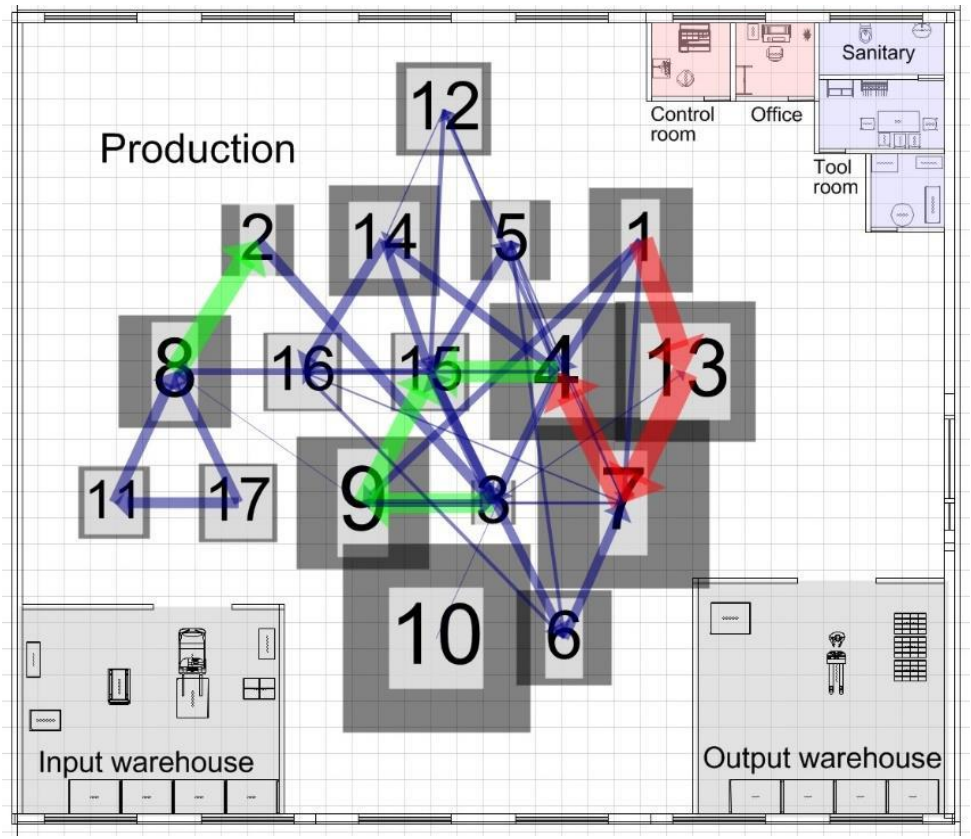

Figure 3: More realistic transformation from Schmigalla method's layout to 2D layout in visTABLE. 


\subsection{Layout modelling and optimization with visTABLE}

As mentioned, first important issue was to place workstation no. 1 near the input warehouse. Therefore, this rearrangement was made by rotating Schmigalla method's layout for 180 degrees. The second step was to connect workstations using real transportation route by keeping Schmigalla method's layout as much as possible. Result is a layout presented in Fig. 4, along with its distance-intensity graph.

From Fig. 4 b, it is clear that high transport intensities (red dots) have small distances among them. However, medium transport intensities (green dots) have some improvement potentials. Using visualization abilities of visTABLE software (material flow visualisation and distance-intensity graph), a manual rearrangement was made. Two variants with different layout, but similar improvement of the transport efficiency were made (Figs. 5 and 6). In Variant II (Fig. 6 b) distances of medium transport intensities (green dots) are better than in Variant I (Fig. 5 b). However, some distances of low transport intensities (blue dots) are worse, so overall improvement of Variant II is not so high. In both variants, transportation route was kept as constant, because there are limited possible modifications of it for this factory layout.

a)

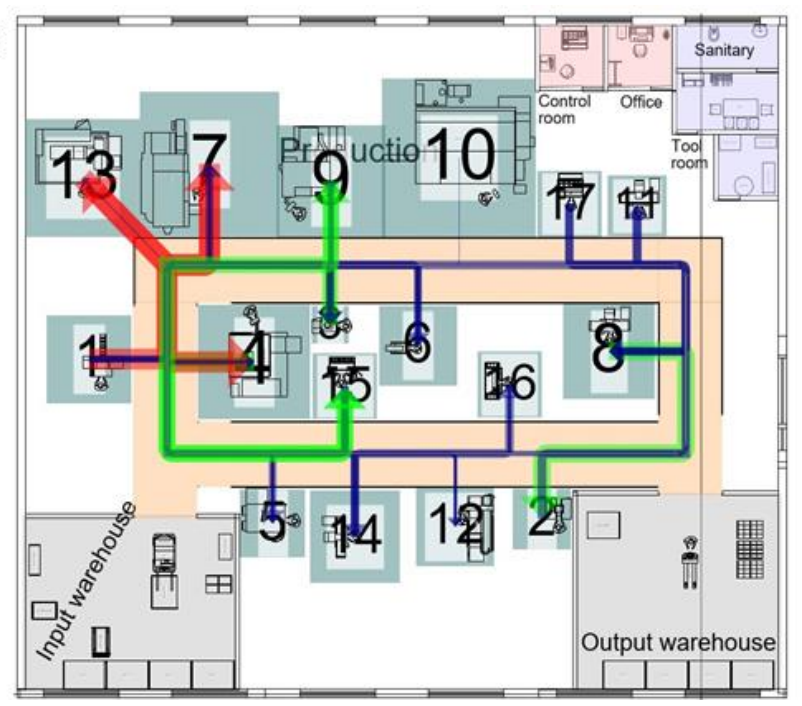

b)

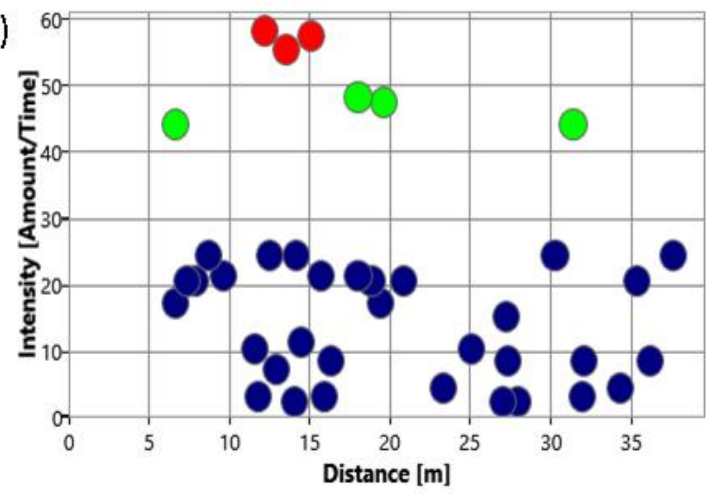

Figure 4: Factory layout and distance-intensity graph of the Schmigalla method's variant.

a)

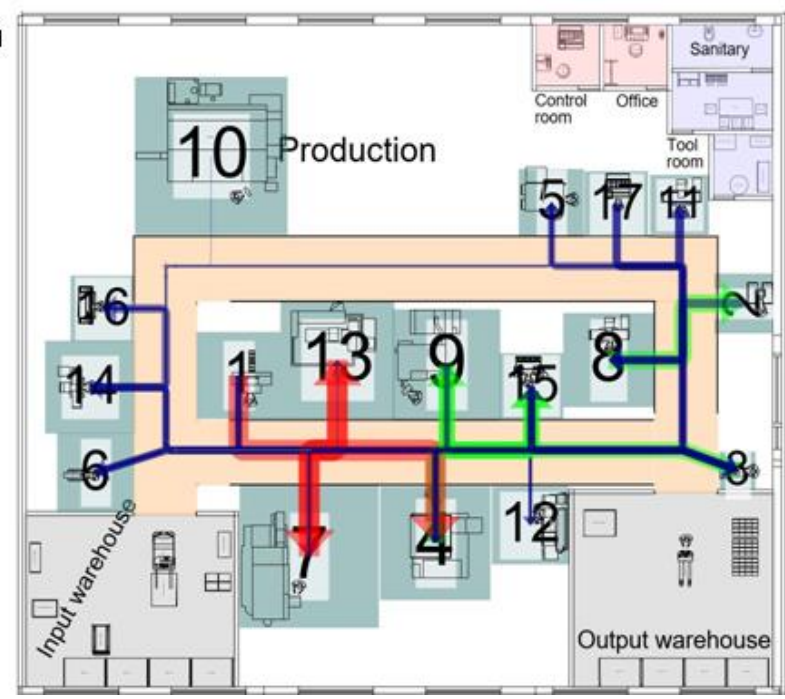

b)

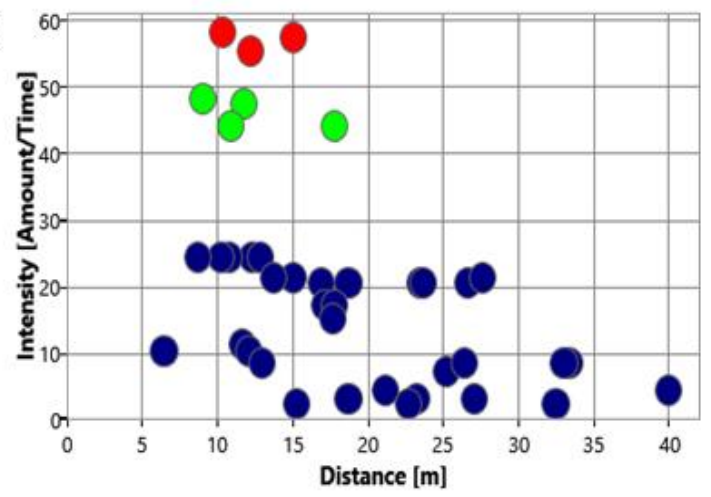

Figure 5: Factory layout and distance-intensity graph of the Variant I (manual rearrangement). 
a)

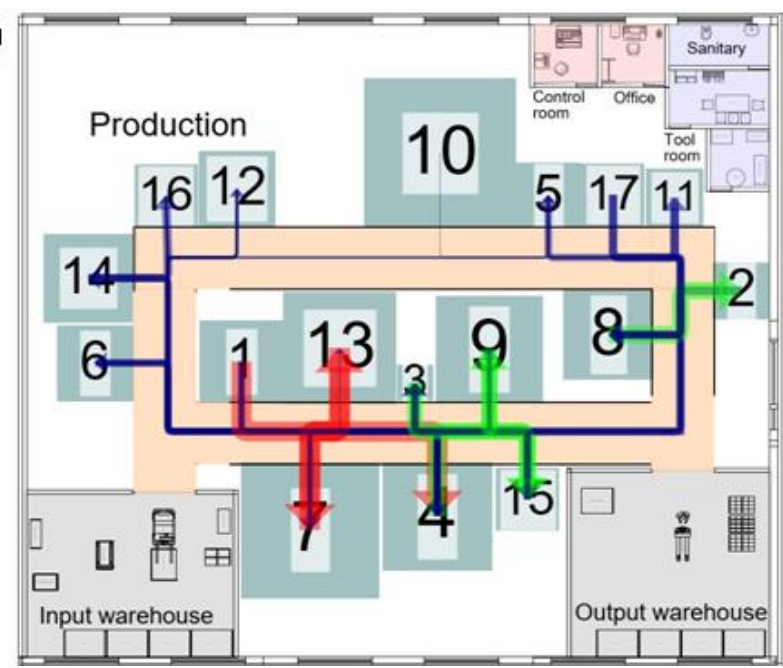

b)

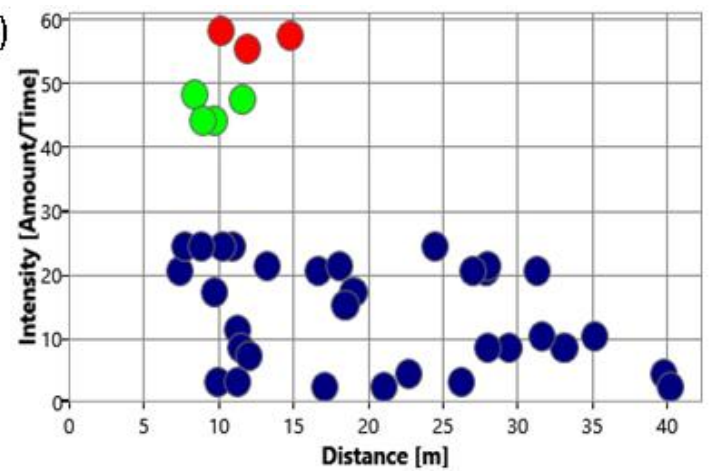

Figure 6: Factory layout and distance-intensity graph of the Variant II (manual rearrangement).

\section{RESULTS AND DISSCUSION}

Presented research addressed problems related to FLP based on Schmigalla method. Combination of Schmigalla method and software tool visTABLE was very helpful in many aspects. Main purpose of this research was minimization of travelling distances on real physical factory layout. Schmigalla method was taken for input as mathematical and theoretical model. Key problem with Schmigalla method is a transformation phase, because all areas of workstations have same value, and distances between them are the same, also. Here software visTABLE had a very good role. During the transformation phase, in the visTABLE were imported realistic areas of workstations. Furthermore, visTABLE has 3D options, so objectivity degree was very high (Fig. 7). Objectivity is one of shortcomings of Schmigalla method, also.



Figure 7: Factory layout in 3D.

As already mentioned, Schmigalla method results with a very good layout, but it is usually not the optimal one. In this research, the focus was not to find optimal layout for workstations on triangular network, but to find their optimal layout in a real factory with all real-world constraints. Therefore Schmigalla method was used just to suggest an initial layout. After that, using visualization abilities of visTABLE software (material flow visualisation and distanceintensity graph), a manual rearrangement was made. Two variants were presented. 
In Table VI, a comparison of proposed layout variants is given. Two variants, made by manual rearrangement of the initial layout, are almost $15 \%$ better than the Schmigalla method's layout. This improvement means $15 \%$ less fuel (or battery) consumption of a forklift. If diesel forklifts are used, then it's not just an economic improvement, but also ecological, since it means less $\mathrm{CO}_{2}$ emission by diesel forklifts.

Table VI: Comparison of proposed layout variants.

\begin{tabular}{|l|c|c|}
\hline \multicolumn{1}{|c|}{ Layout variant } & $\begin{array}{c}\text { Transport efficiency } \\
(\text { meter } \text { units / year) }\end{array}$ & $\begin{array}{c}\text { Improvement } \\
(\boldsymbol{\%})\end{array}$ \\
\hline Schmigalla method's variant & 13862.81 & - \\
\hline Variant I (manual rearrangement) & 11829.02 & $14.67 \%$ \\
\hline Variant II (manual rearrangement) & 11820.91 & $14.72 \%$ \\
\hline
\end{tabular}

\section{CONCLUSION}

This research was realized on a real example of factory layout planning adjusted according to the problems related to Schmigalla method. Software visTABLE has possibility of making virtual 3D environments and layout optimization, but without mathematical input and theoretical model. On the other hand, Schmigalla method has many constraints which can be solved with visTABLE. Therefore, this method and software tool made a perfect combination in this research.

Main problem was transformation of Schmigalla method's layout to real 2D layout. This problem was addressed with software visTABLE. Software visTABLE showed to be more than just VR software. Because of the possibility to manipulate with workstations individually, better solutions for workstations' layout were found. That means that Schmigalla method is not so accurate and reliable by itself, and recommendation is to combine it with some other methods or tools. Another constraint of Schmigalla method is a problem with finding of optimal solution for making triangular network. Some authors combined it with genetic algorithms and better results were achieved.

However, in this research, the focus was not to find an optimal layout for workstations on triangular network, but to find their optimal layout with all real-world constraints. Therefore, Schmigalla method was used just to suggest an initial layout, and then manual rearrangement with visTABLE was made. Two variants of layout, $15 \%$ better than the Schmigalla method's layout, were presented.

Main advantages of this combination are in decrease of travelling distances, which saves lot of time and money to companies. Software visTABLE showed as a very good solution for addressing of shortcomings related to Schmigalla method, especially in transformation phase from triangular network to 2D layout.

Future research should be mainly oriented on a model for easier and more accurate transformation from triangular network to real 2D layout. Since, Schmigalla method isn't much accurate for finding an optimal solution for triangular network, in some future work it should be combined with some optimization methods or tools, like genetic algorithms, ant colony optimization, etc.

\section{ACKNOWLEDGEMENT}

This paper has been supported by Croatian Science Foundation under the project Innovative Smart Enterprise - INSENT (1353). This publication also has been supported by the European Commission under the Erasmus Mundus project Green-Tech-WB: Smart and Green technologies for innovative and sustainable societies in Western Balkans (551984-EM-1-2014-1-ES-ERA MUNDUS-EMA2). 


\section{REFERENCES}

[1] Sule, D. R. (2008). Manufacturing facilities: location, planning, and design, $3^{\text {rd }}$ edition, CRC Press, Northwest, Washington, D.C.

[2] Tompkins, J. A.; White, J. A.; Bozer, Y. A.; Tanchoco, J. M. A. (2010). Facilities planning, $4^{\text {th }}$ edition, John Wiley \& Sons, Danvers

[3] Xiao, Y. J.; Zheng, Y.; Zhang, L. M.; Kuo, Y. H. (2016). A combined zone-LP and simulated annealing algorithm for unequal-area facility layout problem, Advances in Production Engineering \& Management, Vol. 11, No. 4, 259-270, doi:10.14743/apem2016.4.225

[4] Heragu, S. S. (2008). Facilities design, CRC Press, Northwest, Washington, D.C.

[5] Rosenblatt, M. J. (1986). The dynamics of plant layout, Management Science, Vol. 32, No. 1, 7686, doi: $10.1287 / \mathrm{mnsc} .32 .1 .76$

[6] Drira, A.; Pierreval, H.; Hajri-Gabouj, S. (2007). Facility layout problems: A survey, Annual Reviews in Control, Vol. 31, No. 2, 255-267, doi:10.1016/j.arcontrol.2007.04.001

[7] Singh, S. P.; Sharma, R. R. K. (2006). A review of different approaches to the facility layout problems, The International Journal of Advanced Manufacturing Technology, Vol. 30, No. 5-6, 425-433, doi: $10.1007 / \mathrm{s} 00170-005-0087-9$

[8] Kanduc, T.; Rodic, B. (2016). Optimisation of machine layout using a force generated graph algorithm and simulated annealing, International Journal of Simulation Modelling, Vol. 15, No. 2, 275-287, doi:10.2507/IJSIMM15(2)7.335

[9] Ficko, M.; Palcic, I. (2013). Designing a layout using the modified triangle method, and genetic algorithms, International Journal of Simulation Modelling, Vol. 12, No. 4, 237-251, doi:10.2507/IJSIMM12(4)3.244

[10] Centobelli, P.; Cerchione, R.; Murino, T.; Gallo, M. (2016). Layout and material flow optimization in digital factory, International Journal of Simulation Modelling, Vol. 15, No. 2, 223-235, doi:10.2507/IJSIMM15(2)3.327

[11] Schmigalla, H. (1970). Methoden zur optimalen Maschinenanordnung, VEB Verlag Technik, Berlin

[12] Veža, I.; Bilić, B.; Bajić, D. (2001). Projektiranje proizvodnih sustava, Sveučilište u Splitu, Fakultet elektrotehnike, strojarstva i brodogradnje, Split

[13] Krolczyk, J. B.; Krolczyk, G. M.; Legutko, S.; Napiorkowski, J.; Hloch, S.; Foltys, J.; Tama, E. (2015). Material flow optimization - a case study in automotive industry, Technical Gazette, Vol. 22, No. 6, 1447-1456, doi:10.17559/TV-20141114195649

[14] Schmigalla, H. (1995). Fabrikplanung und Zusammenhänge, Fachbuchverlag, Leipzig

[15] visTABLE ${ }^{\circledR}$ touch, visTABLE - Factory layout planning software, from http://www.vistable.de/, accessed on 22-08-2016

[16] Müller, E.; Spanner-Ulmer, B. (Eds.). (2006). Tagungsband Vernetzt planen und produzieren VPP 2006, Technische Universität Chemnitz, Institut für Betriebswissenschaften und Fabriksysteme, Chemnitz

[17] Horejsi, P.; Polcar, J. (2013). An unconventional software environment for factory layout design and automated converter, MM Science Journal, Vol. 6, No. 4, 444-447, doi:10.17973/MMSJ.2013_12_201314

[18] Černý, Z.; Bureš, M. (2008). System approach for production organism design, Proceedings of the $12^{\text {th }}$ International Research/Expert Conference - TMT 2008, 1313-1316

[19] Horbach, S.; Ackermann, J.; Müller, E.; Schütze, J. (2011). Building blocks for adaptable factory systems, Robotics and Computer-Integrated Manufacturing, Vol. 27, No. 4, 735-740, doi:10.1016/j.rcim.2010.12.011

[20] Spath, D.; Müller, F.; Scholtz, O.; Busch, M. (2006). Visuelle mitarbeiterorientierte Montageplanung, Werkstattstechnik, Vol. 96, No. 9, 582-586

[21] Szendrei, D.; Teich, T.; Unger, K.; Militzer, J. (2010). Eine integrierte betriebswirtschaftliche Fallstudie mit SAP ERP und deren Einbindung in das SAP LEGO Labor, Proceedings of the Multikonferenz Wirtschaftsinformatik - MKWI 2010, 1637-1647 